\title{
A Lean Lady With Acanthosis Nigricans and Uncontrolled Diabetes Mellitus
}

\author{
Gururaja Rao $^{1}$, Yash V. Chauhan ${ }^{1}$, Premlata K. Varthakavi ${ }^{1}$, Nikhil Bhagwat ${ }^{1}$ \\ 1. Department of Endocrinology, Topiwala National Medical College and Bai Yamunabai Laxman Nair Charitable \\ Hospital, Mumbai, IND
}

Corresponding author: Nikhil Bhagwat, bhagwatnik@yahoo.co.in

\begin{abstract}
A 47-year-old Asian Indian woman presented with uncontrolled hyperglycaemia and osmotic symptoms despite multiple oral antidiabetic medications and insulin. She had a history of recurrent oral ulcers, profound weight loss, and intermittent fever for one and a half years before the presentation. She had severe acanthosis nigricans, although her body mass index (BMI) was $14.6 \mathrm{~kg} / \mathrm{m}^{2}$.

Her blood glucose remained uncontrolled despite very large dosages of intravenous insulin (more than 12,000 units daily). Evaluation for possible underlying collagen vascular diseases and malignancies were negative. Her serum insulin levels were high. She tested negative for anti-insulin antibodies but positive for anti-insulin-receptor antibodies. She improved with a pulse dose of intravenous methylprednisolone but relapsed within one month. A second pulse dose was given following which a complete remission of diabetes and regression of acanthosis was observed.
\end{abstract}

Type B insulin resistance, a rare cause of severe insulin resistance, may respond favourably to immunosuppressive therapy with high-dose methylprednisolone.

Review began 10/17/2020 Review ended 10/24/2020 Published 11/04/2020

\section{○ Copyright 2020}

Rao et al. This is an open access article distributed under the terms of the Creative Commons Attribution License CC-BY 4.0., which permits unrestricted use, distribution, and reproduction in any medium, provided the original author and source are credited.
Categories: Endocrinology/Diabetes/Metabolism, Internal Medicine, Rheumatology

Keywords: type b insulin resistance, diabetes, acanthosis nigricans, steroids, insulin, antibodies, anti-insulinreceptor, systemic lupus erythematosis

\section{Introduction}

Type B insulin resistance is a rare cause of uncontrolled diabetes mellitus. It is caused by autoantibodies against insulin receptors and may often require very high doses of insulin. It is most commonly associated with systemic lupus erythematosus and other connective tissue disorders and less commonly with malignancies [1]. These associated diseases should be investigated and treated appropriately.

\section{Case Presentation}

A 47-year-old postmenopausal Asian Indian woman was referred for management of uncontrolled diabetes mellitus. She was diagnosed to have Type 2 diabetes mellitus three months prior to presentation when she was evaluated for osmotic symptoms. Her recent fasting and postprandial blood glucose levels were 305 and $416 \mathrm{mg} / \mathrm{dL}$, respectively, despite high doses of multiple oral antidiabetic drugs (metformin 1,500 mg/day, glimepiride $6 \mathrm{mg} /$ day, pioglitazone $15 \mathrm{mg} /$ day). The hyperglycaemia had been unresponsive even to increasing dosages of insulin (multiple-dose injection insulin therapy with regular and neutral protamine Hagedorn (NPH) insulin of > 300 units/day). On inquiry, she had a history of recurrent oral ulcers, profound weight loss of $30 \mathrm{kgs}$ over one and a half years, and intermittent fever without localising symptoms.

On examination, she was emaciated. Her body mass index (BMI) was $14.6 \mathrm{~kg} / \mathrm{m}^{2}$. She had extensive and severe generalised acanthosis nigricans over the nape and axillae with skin tags (Figure 1). Bilateral axillary lymph nodes were palpable. The systemic examination was otherwise unremarkable; in particular, there was no arthritis, serositis, or uveitis. 


\section{Cureus}

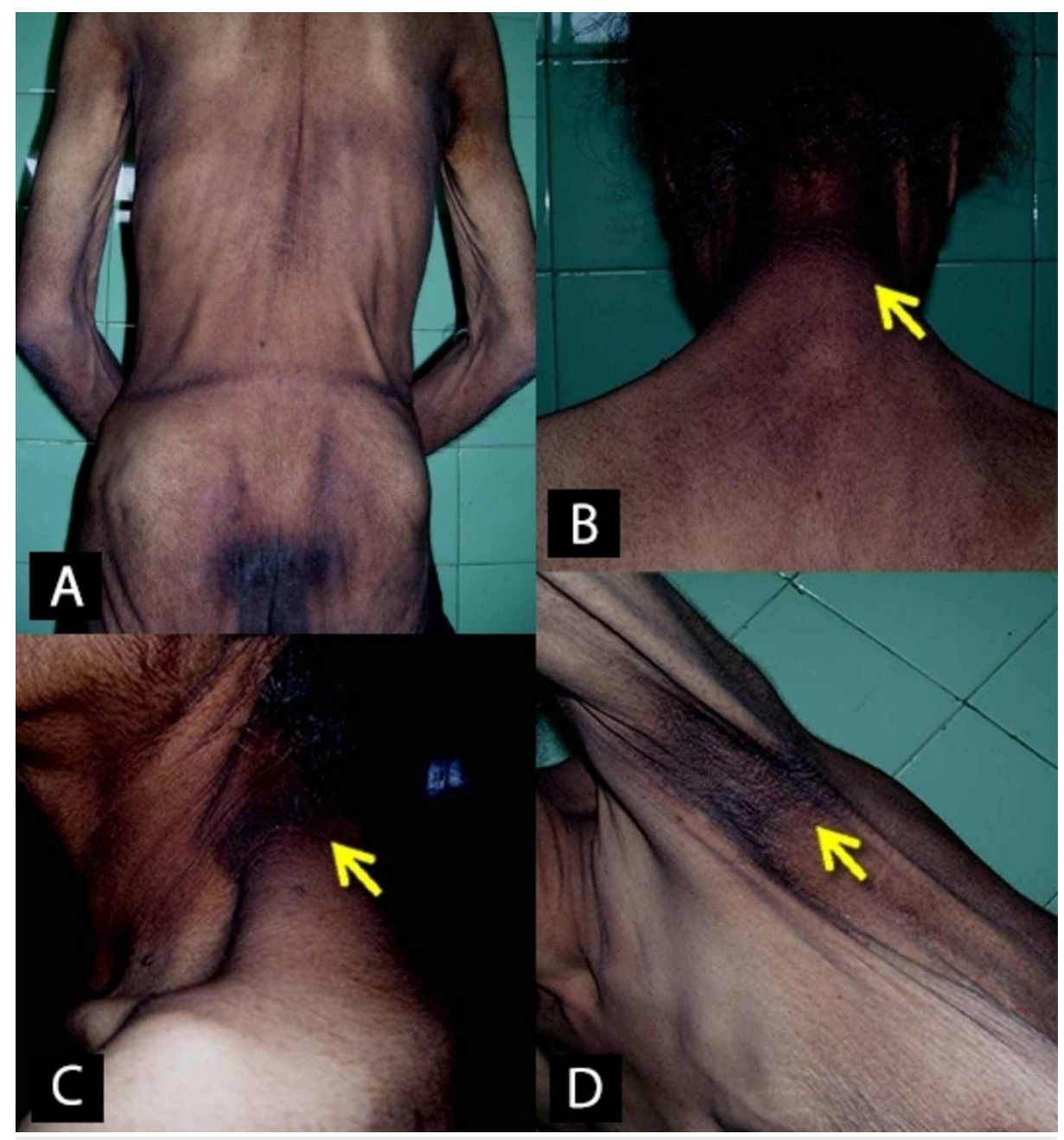

\section{FIGURE 1: Extensive acanthosis nigricans over the body}

A: upper and lower back; B and C: neck, D: axillary region

The patient was admitted and started on basal-bolus insulin therapy, along with metformin (1,500 mg/day) and pioglitazone (15 mg/day). Despite high doses of subcutaneous insulin, her blood glucose ranged between $400-600 \mathrm{mg} / \mathrm{dL}$ and her osmotic symptoms persisted. She was then started on intravenous insulin through an infusion pump. Despite increasing the insulin dose to more than 400 units/hour and 12,000 units daily, her blood glucose remained elevated.

On evaluation, she had low haemoglobin ( 8.8 gm\%), leukopenia, normal platelet counts, and elevated erythrocyte sedimentation rate $(40 \mathrm{~mm} / 1 \mathrm{st} \mathrm{hr})$. Liver and renal function tests were normal. Hemoglobin A1c (HbA1c) at admission was $15.7 \%$. Urinalysis revealed glycosuria but was negative for protein, ketone bodies, and blood. Fasting serum insulin done prior to initiating insulin was elevated $(150 \mathrm{mU} / \mathrm{L})$ and anti-insulin antibodies were negative ( $<10 \%$ binding). Antinuclear antibody (ANA) was positive and showed a speckled appearance, but anti-double-stranded deoxyribonucleic acid (dsDNA) antibodies were negative. Anti-thyroid peroxidase antibodies were positive (1:100); however, she was euthyroid.

As our patient had severe acanthosis and uncontrolled diabetes despite very high dosages of insulin, syndromes of severe insulin resistance (defined as a daily insulin requirement of $>3$ units $/ \mathrm{kg}$ ) were suspected [2]. Various causes of severe insulin resistance that were considered are listed in Table 1 [2-4]. 


\section{Cureus}

The various causes of severe insulin resistance that were considered: (Adapted from[2-4])

\section{Primary insulin signaling defects}

A) Generalised/insulin receptoropathies

- Type A insulin resistance syndrome

- Rabson-Mendenhall syndrome

- Leprechaunism/Donohue syndrome

- HAIR-AN syndrome

B) Partial - AKT2 mutation, SHORT syndrome (PI3KR1 mutation)

\section{Secondary to adipose tissue abnormalities}

A) Severe obesity

B) Lipodystrophy syndromes

1) Congenital

- Congenital generalised lipodystrophy (AGPAT2, BSCL2, CAV1, PTRF mutations)

- Familial partial lipodystrophy (LMNA, PPARG, ZMPSTE24, AKT2, CIDEC mutations)

2) Acquired

- Acquired generalised lipodystrophy (associated with other autoimmune diseases)

- Acquired partial lipodystrophy (HIV-associated, C3 nephritic factor-associated)

\section{Immunologic, autoimmune}

- Type B insulin resistance syndrome

- Antibodies to insulin

IV. Disorders of unknown aetiology - Pseudo-acromegalic insulin resistance

\section{TABLE 1: Classification of Syndromes of Severe Insulin Resistance}

HAIR-AN syndrome: hyperandrogenism (HA), insulin resistance (IR) and acanthosis nigricans (AN); HIV: human immunodeficiency virus; SHORT syndrome: short stature, hyperextensibility, hernia, ocular depression, Rieger anomaly, and teething delay

Given her age and evidence of associated autoimmunity, a clinical diagnosis of Type B insulin resistance syndrome (IRS) due to antibodies against the insulin receptor was considered (Table 2) [5-6]. Serial serum samples were preserved at $-20^{\circ} \mathrm{C}$ for assaying anti-insulin-receptor antibodies later. 


\section{Cureus}

\begin{tabular}{|c|c|c|c|c|c|}
\hline & Type A IRS & Type B IRS & $\begin{array}{l}\text { Rabson- } \\
\text { Mendenhall } \\
\text { Syndrome / } \\
\text { Donohue } \\
\text { Syndrome }\end{array}$ & Lipodystrophy* & $\begin{array}{l}\text { Our } \\
\text { patient }\end{array}$ \\
\hline $\begin{array}{l}\text { Age at } \\
\text { presentation }\end{array}$ & $\begin{array}{l}\text { Adolescents or } \\
\text { young adults }\end{array}$ & $\begin{array}{l}\text { Most common in middle } \\
\text { age; presenting age } \\
\text { ranged from } 10 \text { to } 68 \\
\text { years }\end{array}$ & $\begin{array}{l}\text { First 1-2 years of } \\
\text { life }\end{array}$ & Varies & $\begin{array}{l}47 \\
\text { years }\end{array}$ \\
\hline $\begin{array}{l}\text { Autoimmune } \\
\text { features }\end{array}$ & - & + & - & - & + \\
\hline $\begin{array}{l}\text { Acanthosis } \\
\text { nigricans }\end{array}$ & + & + & + & \pm & + \\
\hline $\begin{array}{l}\text { Dysmorphic } \\
\text { features }\end{array}$ & - & - & + & - & - \\
\hline $\begin{array}{l}\text { Complete/partial } \\
\text { loss of } \\
\text { subcutaneous } \\
\text { fat }\end{array}$ & - & - & - & + & - \\
\hline Cause & $\begin{array}{l}\text { INSR gene, } \\
\text { Intracellular } \\
\text { domain of } \\
\text { tyrosine kinase }\end{array}$ & $\begin{array}{l}\text { Autoantibodies against } \\
\text { insulin receptors }\end{array}$ & $\begin{array}{l}\text { Extracellular } \\
\text { domain of tyrosine } \\
\text { kinase }\end{array}$ & $\begin{array}{l}\text { Genes affecting insulin signaling, } \\
\text { caveolins, phospholipid } \\
\text { biosynthesis, adipogenesis, and } \\
\text { lipolysis }\end{array}$ & \\
\hline
\end{tabular}

\section{TABLE 2: Syndromes of Severe Insulin Resistance}

*Lipodystrophy includes congenital and acquired forms of complete and partial lipodystrophy

IRS - insulin resistance syndrome

Further investigations done to rule out connective tissue disorders and malignancies were unremarkable. Xray of the chest, ultrasonography of the abdomen and pelvis, and skeletal survey for osteolytic lesions were normal. A pap smear was negative for atypical lesions. Biopsy of axillary lymph nodes showed reactive lymphadenopathy. Bone marrow aspiration and biopsy revealed micronormoblastic erythropoiesis. A wholebody ${ }^{18}$ F-fluorodeoxyglucose positron emission tomography $\left({ }^{18} \mathrm{FDG}\right.$-PET-CT) scan did not show any abnormal pathology. Serum protein electrophoresis showed the absence of an M band. Antineutrophil cytoplasmic antibodies and anti-cardiolipin antibodies were negative, and serum complements (C3 and C4) were within the normal reference range.

She did not respond to oral prednisolone (1 $\mathrm{mg} / \mathrm{kg}$ body weight daily) given for four weeks. In keeping with the clinical diagnosis of Type B IRS, she was pulsed with intravenous methylprednisolone (1 gm/day for three days), followed by a maintenance dose of oral prednisolone, $20 \mathrm{mg}$ daily. After two weeks of post-pulse therapy, she achieved euglycemia without any anti-diabetic therapy.

Despite no carbohydrate restriction, she developed spontaneous episodes of hypoglycaemia, which resolved in two to three days. One month after pulse therapy, her blood glucose levels gradually started increasing, indicating a possible relapse. She was then given a single dose of $1 \mathrm{gm}$ intravenous methylprednisolone followed by oral prednisolone and discharged at a dose of $15 \mathrm{mg}$ daily.

The preserved serial serum samples were later sent to the Wellcome Trust-Medical Research Council (MRC) Institute of Metabolic Science, Cambridge, United Kingdom (UK) for assay of the anti-insulin-receptor antibodies using the immunoprecipitation technique. The antibodies were strongly positive, confirming the diagnosis of Type B IRS. The post-hoc analysis demonstrated a correlation between the fall in antibody titre and resolution of hyperglycaemia as shown in Figure 2. 


\section{Cureus}
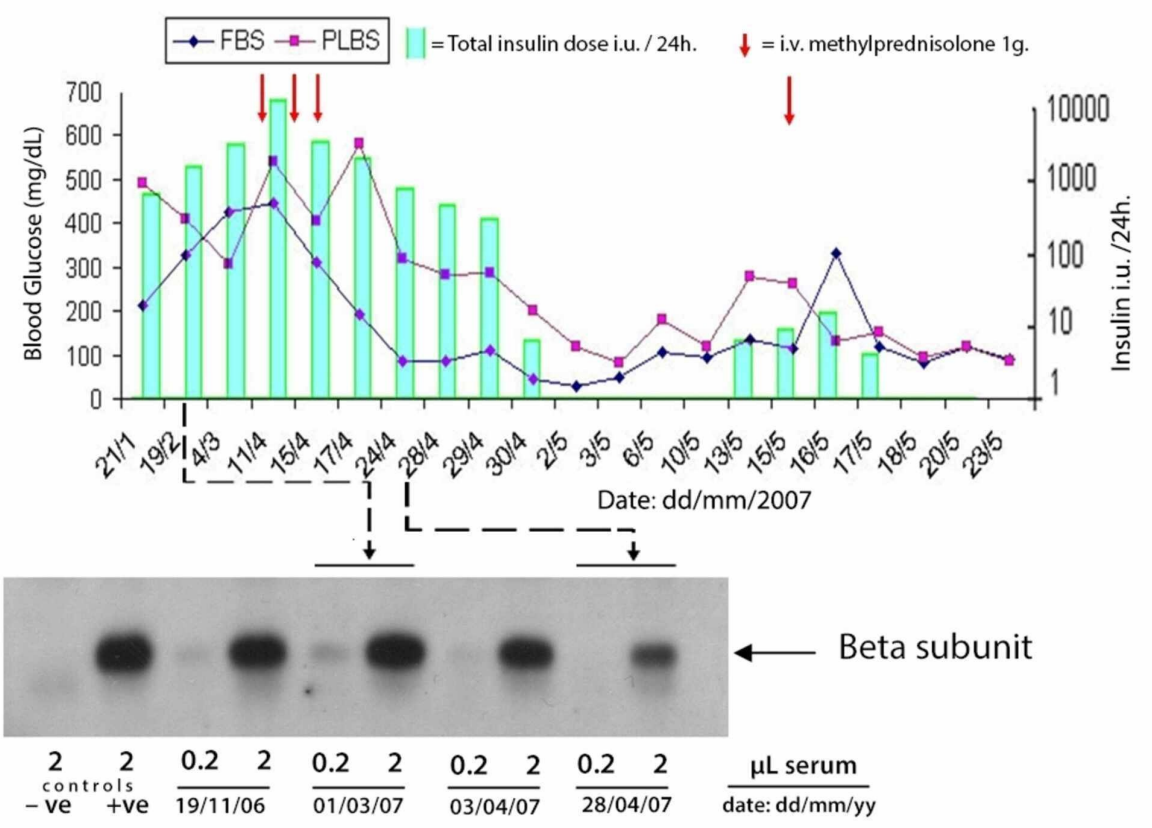

FIGURE 2: Insulin receptor antibodies (immunoprecipitation of soluble insulin receptors by patient's serum)

This figure demonstrates the resolution of hyperglycaemia correlating with a fall in the antibody titre.

FBS: fasting blood sugar; PLBS: post-lunch blood sugar; - ve: negative control; + ve: positive control

At the two-week follow-up, she was asymptomatic, had gained weight, and the acanthosis was regressing (Figure 3). Her blood glucose was within range without any anti-diabetic therapy. The oral steroids were gradually tapered following this visit. 


\section{Cureus}

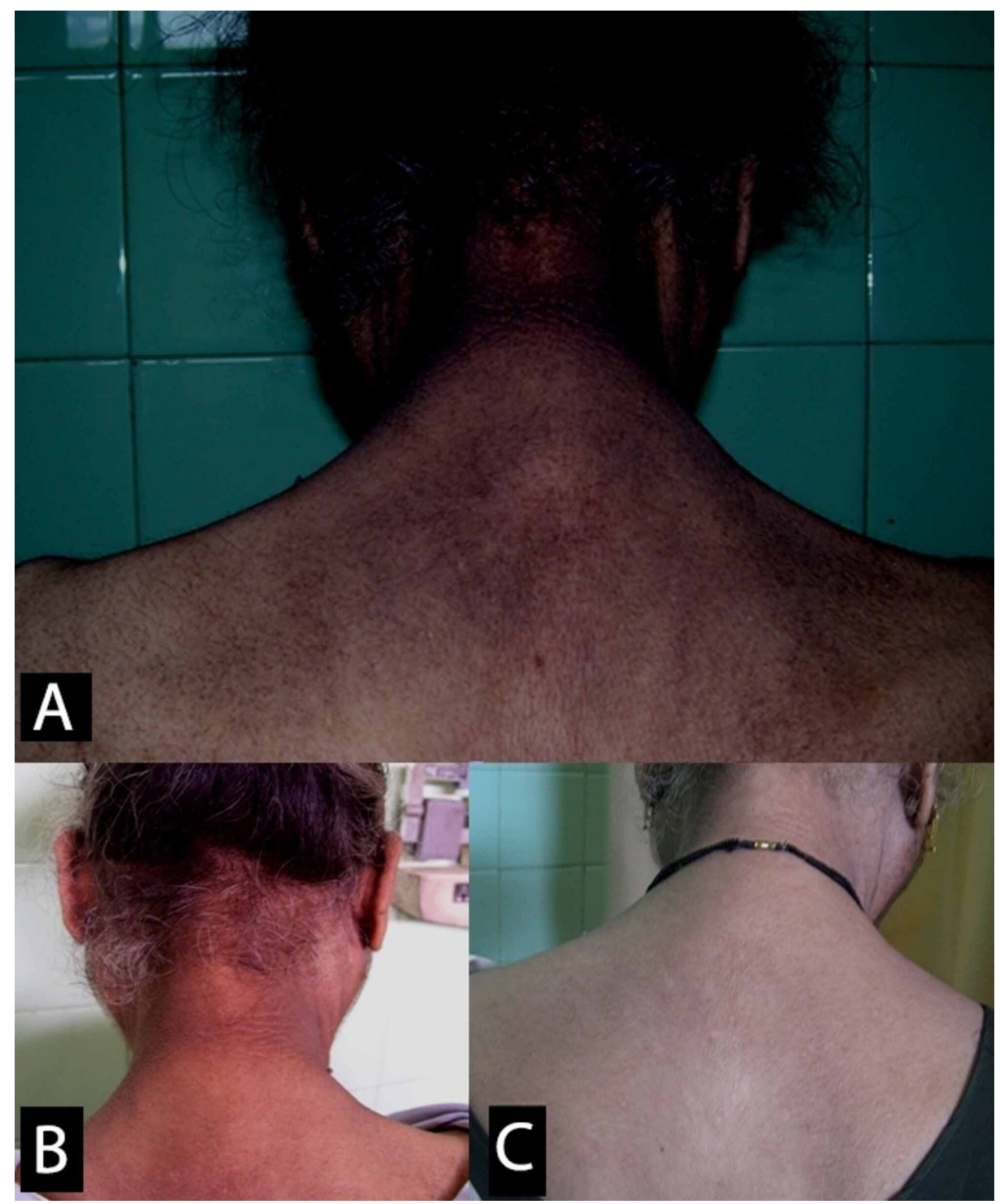

\section{FIGURE 3: Resolution of acanthosis nigricans}

A: before treatment; B: at two weeks post-discharge; C: at the two-year follow-up

Two years after the pulse therapy, she was still euglycemic, and the acanthosis had regressed completely. However, a year after her last follow-up, she was involved in a vehicular accident and passed away.

\section{Discussion}

Type B IRS is an extremely rare cause of uncontrolled diabetes mellitus caused by autoantibodies to the insulin receptor. It is more common in middle-aged females, correlating with the incidence of other autoimmune diseases. The exact prevalence is not known [7-8]. By far, the most information comes from the cohort of 24 patients studied by the National Institutes of Health (NIH) over 28 years [9].

The concept of insulin receptor autoantibodies was first proposed by Flier and Kahn et al., who found a "factor" in the sera of six non-obese acanthotic women with reduced insulin responsiveness and then documented these antibodies a year later [10-11].

The antibodies are predominantly of IgG class and are believed to be inhibitory at high titres and stimulatory at low titres [1]. This may explain the spontaneous hypoglycaemia in our patient two weeks after the pulse therapy which resolved within two to three days.

The formation of antibodies is almost always part of another autoimmune disease, most often systemic lupus erythematosus (SLE). Our patient was positive for the antinuclear antibody (ANA) which was present in $83 \%$ of the NIH cohort [9]. However, our patient did not have any other features of SLE, had normal C3 


\section{Cureus}

and C4 levels, and was negative for anti-dsDNA, whilst $46 \%$ of the NIH study cohort fulfilled the SLE criteria. The NIH study findings are summarised in Table 3.

\begin{tabular}{|c|c|c|}
\hline Clinical Features of Autoimmunity & NIH Series & Our Patient \\
\hline ANA & $83 \%$ & + \\
\hline Hypoalbuminemia & $63 \%$ & + \\
\hline Leukopenia & $63 \%$ & + \\
\hline Elevated ESR & $75 \%$ & + \\
\hline Proteinuria & $54 \%$ & + \\
\hline Serum IgG & $46 \%$ & + \\
\hline High serum anti-dsDNA & $33 \%$ & - \\
\hline Elevated serum IgA & $25 \%$ & - \\
\hline Alopecia & $25 \%$ & - \\
\hline Skin rash & $21 \%$ & - \\
\hline Low C3 & $21 \%$ & - \\
\hline Nephritis & $21 \%$ & - \\
\hline Thrombocytopenia & $21 \%$ & - \\
\hline Enlarged salivary glands & $17 \%$ & - \\
\hline Arthritis & $17 \%$ & - \\
\hline Criteria of SLE & $46 \%$ & - \\
\hline
\end{tabular}

\section{TABLE 3: Clinical Features of Type-B Insulin Resistance Syndrome}

ANA: antinuclear antibody; dsDNA: double-stranded deoxyribonucleic acid; ESR: erythrocyte sedimentation rate; IgA: immunoglobulin A; IgG: immunoglobulin G; NIH: National Institutes of Health; SLE: systemic lupus erythematosus

Arioglu et al. [9]

Type B IRS may also be associated with other autoimmune connective tissue, thyroid, dermatologic, hematologic, and hepatic disorders, including primary biliary cirrhosis, scleroderma, dermatomyositis, overlap syndrome, and Hashimoto's thyroiditis. It may be a paraneoplastic manifestation of certain malignancies, most commonly Hodgkin's lymphoma and multiple myeloma [1, 9, 12-13].

Although no formal definition exists, it has been suggested that this syndrome may comprise of a triad of elevating fasting insulin, hyperadiponectinemia, and low or normal fasting triglyceride levels. These features in a patient with acanthosis nigricans, evidence of underlying autoimmune conditions, and uncontrolled hyperglycaemia may be considered diagnostic [1]. This hyperglycaemia often leads to a profound weight loss, and such patients are usually lean. Consistent with the hyperglycaemic NIH cohort, $80 \%$ of whom had a BMI $<30 \mathrm{~kg} / \mathrm{m}^{2}$, our patient had a BMI of $14.6 \mathrm{~kg} / \mathrm{m}^{2}$. Hypoglycaemia was the initial presentation in only $13 \%$ of the NIH cohort and $67 \%$ of them had a BMI $>30 \mathrm{~kg} / \mathrm{m}^{2}$ [9]. Spontaneous hypoglycaemia has been reported in $23.5 \%$ of patients at some phase of their disease [14].

Management of hyperglycaemia in Type B IRS often involves large dosages of insulin. Management of hyperglycaemia in Type B IRS often involves large dosages of insulin; as much as 150,000 units/day has been reported in the past [15]. Our patient was still uncontrolled despite 12,000 units of insulin daily. Our patient also developed thrombophlebitis of the upper limb veins, possibly due to the phenolic preservative, which can be overcome by the administration of a more concentrated form of insulin. Insulin sensitizers, such as metformin and pioglitazone, may be used for glycaemic control; however, these patients often demonstrate persistent insulin resistance, despite high doses of these agents [16]. Liraglutide has also been successfully used to achieve complete glycaemic control [17].

Immunomodulation is the therapy of choice to induce remission (defined as the amelioration of 
hyperglycemia and discontinuation of insulin therapy) [18]. Various modalities have been employed in the past, albeit with extremely inconsistent remission and high mortality rates. These include high-dose corticosteroids, plasmapheresis, intravenous immunoglobulins, and other immunosuppressants, such as mycophenolate mofetil, cyclophosphamide, cyclosporine, and azathioprine [1, 9, 19-20]. More recently, a standardised protocol has been developed by the NIH consisting of high-dose corticosteroids, cyclophosphamide, and rituximab as induction agents, followed by maintenance therapy with azathioprine or cyclosporine. Significantly higher remission rates ( $86.4 \%$ vs $41.4 \%$ ), lower duration to remission (five months vs 30 months), and lower mortality ( $0 \%$ vs $44.8 \%$ ) have been reported with this protocol compared to the historical NIH cohort when adjusted for a similar time period [7, 18]. Our patient was fortunate enough that, in an extremely resource-limited setting, she responded favourably to high-dose corticosteroids and remained in remission for at least two years without the need for more expensive treatment, such as rituximab or cyclophosphamide.

At the time of publication of the NIH study, three of the nine patients that were still being followed up were positive for the antibody. In contrast, in our patient, consistent with other literature, improvement in dysglycaemia correlated with a fall in titre of antibodies $[9,13]$. Without treatment, a spontaneous resolution was noted in $33 \%$ of the NIH cohort, while $25 \%$ had spontaneous hypoglycaemia. However, the overall cohort had a striking $54 \%$ mortality, and of note, $23 \%$ of those died from complications of hypoglycaemia.

\section{Conclusions}

Type B insulin resistance has a predilection for middle-aged females. These patients typically present with extensive acanthosis despite a lean phenotype. Possible underlying connective tissue diseases and malignancies should be ruled out in these patients. It can also present as spontaneous hypoglycaemia and is one of the two recognised causes of autoimmune forms of hypoglycaemia, the other being insulin autoimmune syndrome. Immunosuppressive therapy is the modality of choice to induce remission and includes a multitude of therapies, including high-dose corticosteroids, as seen in our case. More recently, elaborate rituximab and cyclophosphamide-based regimens have recently been developed and shown to have better remission rates.

\section{Additional Information \\ Disclosures}

Human subjects: Consent was obtained by all participants in this study. Conflicts of interest: In compliance with the ICMJE uniform disclosure form, all authors declare the following: Payment/services info: All authors have declared that no financial support was received from any organization for the submitted work. Financial relationships: All authors have declared that they have no financial relationships at present or within the previous three years with any organizations that might have an interest in the submitted work. Other relationships: All authors have declared that there are no other relationships or activities that could appear to have influenced the submitted work.

\section{References}

1. Willard DL, Stevenson M, Steenkamp D: Type B insulin resistance syndrome. Curr Opin Endocrinol Diabetes Obes. 2016, 23:318-323. 10.1097/MED.0000000000000263

2. Semple RK, Savage DB, Brierley GV, O'Rahilly S: Syndromes of severe insulin resistance and/or lipodystrophy. Genetic Diagnosis of Endocrine Disorders, 2nd ed. Weiss RE, Refetoff S (ed): Academic Press, Boston; 2016. 307-324. 10.1016/b978-0-12-800892-8.00022-1

3. O'Rahilly S: Insights into obesity and insulin resistance from the study of extreme human phenotypes . Eur J Endocrinol. 2002, 147:435-441. 10.1530/eje.0.1470435

4. Semple RK, Savage DB, Cochran EK, Gorden P, O'Rahilly S: Genetic syndromes of severe insulin resistance. Endocr Rev. 2011, 32:498-514. 10.1210/er.2010-0020

5. Gorden P, Collier E, Roach P: Autoimmune mechanisms of insulin resistance and hypoglycemia . Insulin Resistance. Moller DE (ed): John Wiley \& Sons, New York; 1993. 123-141.

6. Kahn CR, Ferris HA, O'Neill BT: Pathophysiology of type 2 diabetes mellitus. Williams Textbook of Endocrinology, 14th ed. Melmed S, Auchus RJ, Goldfine AB, Koenig RJ, Rosen CJ (ed): Saunders Elsevier, Philadelphia; 2020. 1349-1370.

7. Klubo-Gwiezdzinska J, Lange M, Cochran E, Semple RK, Gewert C, Brown RJ, Gorden P: Combined immunosuppressive therapy induces remission in patients with severe type $B$ insulin resistance: a prospective cohort study. Diabetes Care. 2018, 41:2353-2360. 10.2337/dc18-0884

8. Yu S, Yang G, Dou J, et al.: Comparison of two autoimmune dysglycemia syndromes: insulin autoimmune syndrome (IAS) and type B insulin resistance syndrome (B-IRS). Horm Metab Res. 2019, 51:723-728. 10.1055/a-1005-0071

9. Arioglu E, Andewelt A, Diabo C, Bell M, Taylor SI, Gorden P: Clinical course of the syndrome of autoantibodies to the insulin receptor (type B insulin resistance): a 28 -year perspective. Medicine (Baltimore). 2002, 81:87-100. 10.1097/00005792-200203000-00001

10. Flier IS, Kahn CR, Roth J, Bar RS: Antibodies that impair insulin receptor binding in an unusual diabetic syndrome with severe insulin resistance. Science. 1975, 190:63-65. 10.1126/science.170678

11. Kahn CR, Flier JS, Bar RS, Archer JA, Gorden P, Martin MM, Roth J: The syndromes of insulin resistance and acanthosis nigricans - insulin-receptor disorders in man. N Engl J Med. 1976, 294:739-745. 


\section{Cureus}

10.1056/NEJM197604012941401

12. Walters EG, Tavaré JM, Denton RM, Walters G: Hypoglycaemia due to an insulin-receptor antibody in Hodgkin's disease. Lancet. 1987, 1:241-243. 10.1016/s0140-6736(87)90064-X

13. Fareau GG, Maldonado M, Oral E, Balasubramanyam A: Regression of acanthosis nigricans correlates with disappearance of anti-insulin receptor autoantibodies and achievement of euglycemia in type B insulin resistance syndrome. Metabolism. 2007, 56:670-675. 10.1016/j.metabol.2006.12.016

14. Lupsa BC, Chong AY, Cochran EK, Soos MA, Semple RK, Gorden P: Autoimmune forms of hypoglycemia. Medicine (Baltimore). 2009, 88:141-153. 10.1097/MD.0b013e3181a5b42e

15. Magsino CH Jr, Spencer J: Insulin receptor antibodies and insulin resistance. South Med J. 1999, 92:717-719. 10.1097/00007611-199907000-00013

16. Hong JH, Kim HJ, Park KS, Ku BJ: Paradigm shift in the management of type B insulin resistance . Ann Transl Med. 2018, 6:S98. 10.21037/atm.2018.11.21

17. Matsumoto Y, Yamada H, Funazaki S, Suzuki D, Kakei M, Hara K: Effect of liraglutide on type B insulin resistance syndrome and insulin allergy in type 2 diabetes: a case report. Diabetes Ther. 2017, 8:1191-1194. 10.1007/s13300-017-0291-2

18. Malek R, Chong AY, Lupsa BC, et al.: Treatment of type B insulin resistance: a novel approach to reduce insulin receptor autoantibodies. J Clin Endocrinol Metab. 2010, 95:3641-3647. 10.1210/jc.2010-0167

19. Manikas ED, Isaac I, Semple RK, Malek R, Führer D, Moeller LC: Successful treatment of type B insulin resistance with rituximab. J Clin Endocrinol Metab. 2015, 100:1719-1722. 10.1210/jc.2014-3552

20. Viswanathan L, Sirisena I: Immunosuppressive therapy in treatment of refractory hypoglycemia in type B insulin resistance: a case report. J Endocr Soc. 2017, 1:1435-1439. 10.1210/js.2017-00292 